\title{
PENGARUH KARAKTERISTIK INDIVIDU TERHADAP KINERJA PEGAWAI DI UPT. PENGUJIAN SERTIFIKASI MUTU BARANG - LEMBAGA TEMBAKAU JEMBER
}

Oleh :

\author{
DEVI ARIENI *), TANTI KUSTIARI dan SUHARJONO *)
}

\begin{abstract}
ABSTRAK
Pelaksanaan pemerintahan yang baik (good governance) memerlukan dukungan sumber daya manusia (SDM) yang memiliki karakteristik individu yang baik. Karakteristik merupakan demografi pegawai yang melekat pada pribadi individual melalui ciri-ciri atau sifat-sifat yang dimiliki. Beberapa aspek karakteristik individu yang dinilai adalah sikap, minat kerja, motivasi dan kepatuhan, yang mana dengan adanya karakteristik individu ang baik, maka kinerja pegawai dapat menjadi lebih baik. Penelitian ini bertujuan mengetahui pengaruh karakteristik individu pegawai yang meliputi sikap, minat, motivasi dan kepatuhannya terhadap kinerja pegawau di UPT. PSMB - Lembaga Tembakau Jember. Penelitian ini dilaksanakan di UPT PSMB - Lembaga Tembakau Jember pada bulan Juni hingga Agustus 2015. Jumlah responden adalah 31 orang pegawai UPT PSMB - LT Jember melalui metode sensus atau complete anumeration. Teknik analisis data menggunakan analisis regresi berganda melalui program IBM SPSS 20. Hasil penelitian menunjukkan bahwa karakteristik individu yang meliputi variabel sikap, minat, motivasi dan kepatuhannya memiliki pengaruh positif dan signifikan terhadap kinerja pegawai di UPT. PSMB - Lembaga Tembakau Jember dengan variabel motivasi menjadi variabel dengan koefisien korelasi terbesar terhadap kinerja pegawai yakni 0,335 atau sebesar $11,2 \%$.
\end{abstract}

Kata kunci: karakteristik individu, kepatuhan, minat, motivasi, sikap

\section{PENDAHULUAN}

Keberadaan sumber daya manusia (SDM) dalam organisasi memiliki posisi yang sangat penting. Konsekuensinya, organisasi memerlukan SDM yang memiliki keahlian dan kemampuan yang sesuai dengan visi dan misi organisasi. Agar tujuan organisasi dapat tercapai maka dibutuhkan pegawai yang berkerja secara efisien dan efektif sehingga, memberikan kinerja yang baik. Dan supaya pegawai dapat memberikan kinerja yang baik maka organisasi dapat memberikan dukungan melalui ketersediaan pegawai yang memiliki karakteristik individu yang baik. Pengertian Karakteristik Individu adalah perbedaan individu dengan individu lainnya. Sumber daya yang terpenting dalam organisasi adalah sumber daya manusia, orang-orang yang memberikan tenaga, bakat, kreativitas, dan usaha mereka kepada organisasi agar suatu organisasi dapat tetap eksistensinya.

Unit Pelaksana Teknis Pengujian dan Sertifikasi Mutu Barang - Lembaga Tembakau Jember (UPT PSMB - LT Jember) merupakan unit atau badan yang banyak menangani pengawasan komoditi ekspor, khususnya komoditi tembakau. Keberadaan UPT PSMB LT Jember dianggap penting, terutama bagi perusahaan eksportir tembakau, karena sertifikat hasil uji yang diterbitkan oleh UPT PSMB - LT
Jember menjadi prasyarat dokumen ekspor sebagai sertifikat pengawas mutu komoditi yang diekspor. Ada beberapa jenis pelayanan yang dilakukan oleh UPT PSMB - LT Jember, diantaranya inspeksi tembakau; inspeksi proses fumigasi dan inspeksi kontainer. Dalam melakukan pelayanan tersebut, petugas seringkali mendapatkan kesulitan pada standar pelayanan karena diharuskan mengacu Standar Nasional Indonesia dan Standar Internasional. Hal ini menuntut petugas untuk memiliki pengetahuan dan kemampuan yang baik.

Kinerja seorang pegawai akan lebih baik jika pegawai tersebut memiliki kemampuan yang tinggi yang didukung dari sikap, minat, motivasi dan kepatuhan. Berdasarkan uraian tersebut, penelitian tentang "Pengaruh Karakteristik Individu Terhadap Kinerja Pegawai di UPT PSMB - LT Jember" dianggap penting utuk dilakukan dengan menggunakan pendekatan ilmu Manajemen Sumber Daya Manusia.

\section{Tujuan Penelitian}

Adapun tujuan penelitian ini untuk menguji dan menganalisis Pengaruh karakteristik individu yang meliputi sikap, minat, motivasi dan kepatuhannya terhadap kinerja pegawai UPT. PSMB - Lembaga Tembakau Jember. 
Devi Arieni, Tanti Kustiari dan Suharjono, Pengaruh Karakteristik Individu Terhadap Kinerja Pegawai Di UPT. Pengujian Sertifikasi Mutu Barang-Lembaga Tembakau Jember

\section{KAJIAN TEORI \\ Pengertian Karakteristik Individu}

Sumber daya yang terpenting dalam suatu organisasi adalah sumber daya manusia, orangorang yang memberikan tenaga, bakat, kreativitas dan usaha mereka kepada organisasi agar suatu organisasi tetap berjalan. Setiap manusia mempunyai karakteristik individu yang berbeda beda antara yang satu dengan yang lainnya. Menurut Stoner dalam Nurhastuti (2011) Karakteristik individual adalah keinginan, sikap dan kebutuhan seseorang yang dibawa kedalam situasi kerja. Menurut Robbins (2006) variabel ditingkat individu meliputi karakteristik biografis yakni karakteristik perseorangan yang diperoleh secara mudah dan objektif dari arsip pribadi seseorang misalnya usia, gender, ras dan masa jabatan., kemampuan, kepribadian dan pembelajaran. Menurut Winardi (2004) karakteristik individu mencakup latar belakang keluarga, sosial, dan pengalaman; umur, bangsa, jenis kelamin yang mencerminkan karakteristik psikologis yang terdiri dari persepsi, sikap, kepribadian dan motivasi.Sedangkan menurut Malthis dalam Mahmodha (2004) ada empat karakteristik idividu yang mempengaruhi bagaimana orang-orang dapat berprestasi antara lain:

a. Minat, orang cenderung mengejar karir yang mereka yakini cocok dengan minat mereka.

b. Jati Diri, karir merupakan perpanjangan dari jati diri seseorang juga hal yang membetuk jati diri.

c. Kepribadian, faktor ini mencakup orientasi pribadi karyawan dan kebutuhan individual, latihan, dan kekuasaan.

d. Latar belakang sosial, status sosial ekonomi dan tujuan pendidikan pekerjaan orang tua karyawan merupakan faktor yang berfungsi dalam kategori.

Karakteristik individu adalah ciri yang melekat pada individu yang membedakan individu satu dengan lainnya dan menjadi modal kemampuan kerja.Karakteristik individu merupakan karakter yang ada pada diri seorang karyawan baik yang bersifat positif maupun negatif. Karakteristik-karakteristik ini sangat beragam, setiap perusahaan tentunya dapat memilih seorang karyawan yang mempunyai kriteria yang baik dan karakteristik ini juga harus sesuai dengan apa yang diinginkan perusahaan.

\section{Pengertian Kinerja}

Keberhasilan suatu organisasi dipengaruhi oleh kinerja (job performance) pegawai, untuk itu setiap perusahaan akan berusaha untuk meningkatkan kinerja pegawainya dalam mencapai tujuan organisasi yang telah ditetapkan. Kinerja pada hakekatnya adalah hasil kerjayang dapat dicapai oleh seseorang atau sekelompok orang dalam organisasi, sesuai dengan wewenang dan tanggung jawab masing-masing, dalam rangka mencapai tujuan organisasi. Sedangkan menurut Wirawan (2009), kinerja adalah keluaran yang dihasilkan oleh fungsi-fungsi atau indikatorindikator suatu pekerjaan atau suatu profesi dalam waktutertentu. Kinerja merujuk pada pencapaian pegawai atas tugas yang diberikan (Marifah, 2005).

Kinerja pegawai adalah seberapa banyak pegawai memberi kontribusi kepada organisasi yang antara lain termasuk kuantitas output, kualitas output, jangka waktu output, kehadiran di tempat kerja dan sikap komperatif. Kinerja pegawai merupakan hasil kerja yang dicapai seseorang dalam melaksanakan tugastugas yang dibebankan kepadanya. Kinerja pegawai meliputi kualitas dan kuantitas output serta keandalan dalam bekerja. Pegawai dapat bekerja dengan baik bila memiliki kinerja yang tinggi sehingga dapat menghasilkan kerja yang baik pula. Dengan adanya kinerja yang tinggi yang dimiliki pegawai, diharapkan tujuan organisasi dapat tercapai. Sebaliknya, tujuan organisasi susah atau bahkan tidak dapat tercapai bila pegawainya bekerja tidak memiliki kinerja yang baik sehingga tidak dapat menghasilkan kerja yang baik pula (Lewa, 2005).

\section{METODE PENELITIAN}

Penelitian dilakukan di kantor UPT PSMB - LT Jember yang terletak di Jl. Kalimantan No 1 Jember pada bulan Juni Agustus 2015. Lokasi penelitian ditentukan secara purposive karena UPT PSMB - LT Jember merupakan satu-satunya lembaga yang fokus menangani tembakau yang menjadi komoditi unggulan Kabupaten Jember. Metode pengambilan sampel adalah sensus atau complete anumeration. Menurut Nazir (2005) complete anumeration adalah penentuan responden berdasarkan teknik sensus kepada seluruh anggota populasi, atau dapat dikatakan penelitian ini tidak menggunakan sampel sehingga teknik yang digunakan adalah teknik sampling kepada seluruh pegawai UPT PSMB - LT Jember sebagai populasi. Jumlah sampel penelitian sebanyak 31 orang.

Pengambilan data melalui wawancara dan pengisian kuesioner. Penelitian ini bersifat penelitian penjelasan (explanatory research), karena menjelaskan hubungan kausal antara variabel-variabel melalui pengujian hipotesa.

Kerangka Konseptual Penelitian 


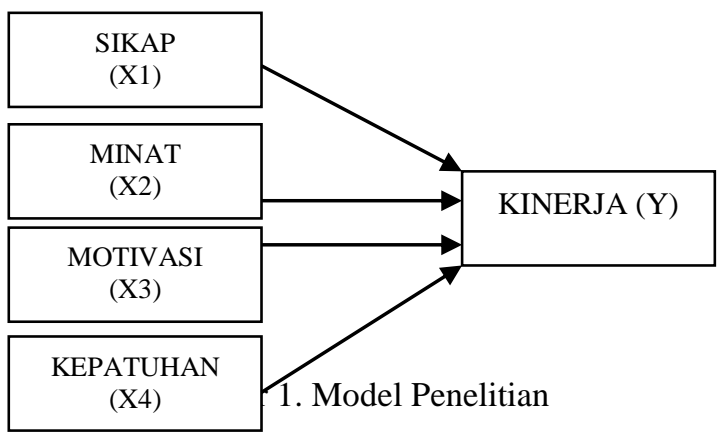

Adapun teknik analisis yang digunakan dalam penelitian ini adalah:

1. Uji Validitas

Uji Validitas bertujuan untuk mengetahui sejauh mana validitas data yang didapat dari pengisian kuisioner melalui wawancara. Uji validitas menggunakan Confirmatory Factor Analysis (CFA) pada software SPSS 20 for windows. Kriteria uji validitas adalah jika nilai sig. (2-tailed) tiap variabel menggunakan pearson correlation < 0.05 , maka variabel tersebut dinyatakan valid dan sebaliknya (Marimin, 2010).

2. Uji Reliabilitas

Uji Reabilitas merupakan uji kehandalan suatu alat ukur apabila pengukuran dilakukan berulang kali pada sampel yang berbeda. Uji realibilitas dilakukan dengan menggunakan metode Cronbach's Alpha dengan Software SPSS 20 for windows. Jika nilai Cronbach's Alpha $\geq 0.60$ dan Probabilitas Sig. F $\leq 0.05$, maka data penelitian dianggap cukup baik dan reliabel untuk digunakan sebagai input dan proses penganalisaan data guna menguji hipotesis penelitian (Ghozaly, 2005).

3. Analisis Data dengan Regresi Berganda Regresi linier berganda digunakan untuk mengetahui pengaruh antara variabel dependen (karakteristik individu) terhadap variabel dependen (kinerja pegawai). Pengaruh antara variabel independen dan variabel dependen diformulasikan dalam persamaan regresi sebagai berikut :

$$
\mathrm{Y}=\gamma \mathrm{X}_{1}+\gamma \mathrm{X}_{2}+\gamma \mathrm{X}_{3}+€_{1}
$$

\section{HASIL DAN PEMBAHASAN Uji Validitas}

Pengujian validitas kuisioner dilakukan pada seluruh pegawai yang menjadi petugas inspeksi di UPT PSMB - LT Jember sejumlah 31 orang. Hasil perhitungan uji validitas terhadap 31 orang pegawai diperoleh nilai koefisiensi dengan rentang 0.362 hingga 0.651 . Instrumen yang valid apabila nilai koefisien memenuhi kriteria $\mathrm{r}$ hitung $>\mathrm{r}$ tabel $(>0.355)$ pada taraf alpha 0.05 .
Dengan demikian dari 22 pertanyaan yang dinilai dinyatakan valid.

\section{Uji Reliabilitas}

Uji reliabilitas dalam penelitian ini dihitung dengan menggunakan metode cronbach alpha. Dari uji terhadap kuisioner diperoleh nilai seperti dalam tabel 1 sebagai berikut:

Tabel 1 Hasil Uji Reliabilitas dengan Cronbach's Alpha pada ANOVA

\section{Reliability Statistics}

\begin{tabular}{|c|c|}
\hline Cronbach's Alpha & N of Items \\
\hline .820 & 22 \\
\hline
\end{tabular}

Hasil uji reliabilitas diatas menunjukkan bahwa variabel karakteristik individu mempunyai koefisien Alpha yang cukup besar yaitu diatas 0,60 sehingga dapat dikatakan semua konsep pengukur pada variabel dari kuesioner adalah reliabel dan layak digunakan sebagai alat ukur.

\section{Analisis Regresi Beganda}

Hasil perhitungan analisis regresi berganda dengan menggunakan program IBM SPSS 20 didapatkan :

Tabel 2. Analisis Persamaan Regresi

\begin{tabular}{|c|c|c|c|c|c|}
\hline \multicolumn{6}{|c|}{ Coefficients $^{\mathrm{a}}$} \\
\hline \multirow[t]{2}{*}{ Model } & \multicolumn{2}{|c|}{$\begin{array}{c}\text { Unstandardized } \\
\text { Coefficients }\end{array}$} & \multirow{2}{*}{\begin{tabular}{c|}
$\begin{array}{c}\text { Standardized } \\
\text { Coefficients }\end{array}$ \\
Beta
\end{tabular}} & \multirow[t]{2}{*}{$\mathrm{t}$} & \multirow[t]{2}{*}{ Sig. } \\
\hline & \begin{tabular}{l|}
$\mathrm{B}$ \\
\end{tabular} & $\begin{array}{l}\text { Std. } \\
\text { Error }\end{array}$ & & & \\
\hline (Constant) & $-66,310$ & 9,325 & & $-7,111$ &, 000 \\
\hline SIKAP & 1,711 & .637 & 237 & 2,686 & 012 \\
\hline 1 MINAT & 2,441 & 697 & 301 & 3,502 &, 002 \\
\hline MOTIVASI & 1,666 & 491 & 335 & 3,393 & 002 \\
\hline KEPATUHAN & 1,309 & 389 & 318 & 3,360 &, 002 \\
\hline
\end{tabular}

a. Dependent Variable: KINERJA

$\mathrm{Uji}$ statistik t pada dasarnya digunakan untuk menunjukan seberapa jauh pengaruh satu variabel independen secara individual/parsial dalam menerangkan variasi variabel dependen. Dari hasil perhitungan dengan menggunakan program IBM SPSS 20, berdasar tabel diatas, dapat dibuat rincian sebagai berikut :

1) Pengaruh Sikap individu terhadap Kinerja Pegawai

\begin{tabular}{|l|r|r|r|c|c|}
\hline Model & \multicolumn{1}{|c|}{ Sum of } & df & Mean & F & Sig. \\
& Squares & & Square & & \\
\hline Regression & 1139,173 & 4 & 284,793 & 51,448 &, $000^{\circ}$ \\
\hline 1 Residual & 143,924 & 26 & 5,536 & & \\
\hline Total & 1283,097 & 30 & & & \\
\hline a. Dependent Variable: KINERJA \\
b.Predictors: (Constant), KEPATUHAN, MINAT, SIKAP, \\
MOTIVASI
\end{tabular}


Devi Arieni, Tanti Kustiari dan Suharjono, Pengaruh Karakteristik Individu Terhadap Kinerja Pegawai Di UPT. Pengujian Sertifikasi Mutu Barang-Lembaga Tembakau Jember

$\mathrm{H}_{1}: \rho_{\mathrm{x} 1 \mathrm{y}} \neq 0$ Sikap individu berpengaruh terhadap kinerja pegawai

Nilai t-hitung untuk sikap individu sebesar 2,686 karena nilai t-hitung lebih besar dibandingkan ttabel $(2,686>2,045)$ maka hipotesis (H1) diterima. Artinya, sikap individu pegawai berpengaruh positif terhadap kinerja pegawai.

2) Pengaruh Minat terhadap Kinerja Pegawai

$\mathrm{H}_{2}: \rho_{\mathrm{x} 1 \mathrm{y}} \neq 0$ Minat berpengaruh terhadap kinerja pegawai

Nilai t-hitung untuk sikap individu sebesar 3,502 karena nilai t-hitung lebih besar dibandingkan ttabel $(3,502>2,045)$ maka hipotesis $\left(\mathrm{H}_{2}\right)$ diterima. Artinya, minat pegawai berpengaruh positif terhadap kinerja pegawai.

3) Pengaruh Motivasi terhadap Kinerja Pegawai

$\mathrm{H}_{3}: \rho_{\mathrm{x} 1 \mathrm{y}} \neq 0$ Motivasi berpengaruh terhadap kinerja pegawai

Nilai t-hitung untuk sikap individu sebesar 3,393 karena nilai t-hitung lebih besar dibandingkan ttabel $(3,393>2,045)$ maka hipotesis $\left(\mathrm{H}_{3}\right)$ diterima. Artinya, motivasi yang dimiliki pegawai berpengaruh positif terhadap kinerjanya.

4) Pengaruh Kepatuhan terhadap Kinerja Pegawai

5) $\mathrm{H}_{4}: \rho_{\mathrm{x} 1 \mathrm{y} \neq 0}$ Kepatuhan berpengaruh terhadap kinerja pegawai

Nilai t-hitung untuk sikap individu sebesar 3,360 karena nilai t-hitung lebih besar dibandingkan ttabel $(3,360>2,045)$ maka hipotesis $\left(\mathrm{H}_{4}\right)$ diterima. Artinya, kepatuhan berpengaruh positif terhadap kinerja pegawai.

\section{Uji F}

Pengujian dimaksud untuk mengetahui pengaruh signifikan antara variabel sikap, minat, motivasi dan kepatuhan terhadap kinerja secara serempak.
Tabel 3. Hasil Analisis Uji F

\begin{tabular}{|c|c|c|c|c|c|}
\hline Model & $\begin{array}{r}\text { Sum of } \\
\text { Squares }\end{array}$ & $\mathrm{df}$ & $\begin{array}{l}\text { Mean } \\
\text { Square }\end{array}$ & F & Sig. \\
\hline Regression & 1139,173 & 4 & 284,793 & 51,448 & $.000^{\mathrm{b}}$ \\
\hline 1 Residual & 143,924 & 26 & 5,536 & & \\
\hline Total & 1283,097 & 30 & & & \\
\hline \multicolumn{6}{|c|}{ a. Dependent Variable: KINERJA } \\
\hline $\begin{array}{l}\text { b. Predictors: } \\
\text { MOTIVASI }\end{array}$ & & & & & \\
\hline
\end{tabular}

Hasil uji ANOVA atau uji $\mathrm{F}$ diperoleh $\mathrm{F}$ hitung sebesar 51,488 dan F tabel sebesar 2,70 $(51,448>2,70)$ dengan tingkat signifikan 0,000 . Oleh karena itu, nilai probabilitasnya lebih kecil dari 0,05 , maka dapat dikatakan bahwa variebal karakteristik individu yang meliputi sikap, minat, motivasi dan kepatuhan secara bersama-sama berpengaruh terhadap kinerja pegawai. Berdasarkan hasil pengujian tersebut dapat disimpulkan bahwa variabel sikap, minat, motivasi dan kepatuhan berpengaruh terhadap kinerja pegawai.

\section{Pembahasan}

Karakteristik merupakan demografi pegawai yang melekat pada pribadi individual melalui ciri-ciri atau sifat-sifat yang dimiliki. Beberapa aspek karakteristik individu yang dinilai adalah sikap, minat kerja, motivasi dan kepatuhan.

\section{Sikap}

Sikap pegawai diukur berdasarkan tingkat loyalitas pegawai terhadap institusi seperti aspek kesediaan melakukan pelayanan pada lokasi yang jaraknya jauh dari kantor dan kesediaan pelayanan pada saat hari libur. Sikap pegawai berada pada kategori sedang. Banyak pegawai memiliki sikap loyal yang baik pada institusi, pegawai bersedia melakukan pelayanan di tempat yang jauh dari Jember, seperti pelayanan di Bojonegoro yang jaraknya lebih dari $300 \mathrm{~km}$ dari Jember serta bersedia melaksanakan pelayanan pada saat hari libur yang bertujuan memenuhi permintaan layanan inspeksi fumigasi dan inspeksi sarana angkut/kontainer.

\section{Minat Kerja}

Minat kerja yang dimiliki pegawai diukur berdasarkan tingkat keinginan pegawai untuk melaksanakan tugas yakni pelayanan pada masyarakat. Berdasarkan hasil penilaian, minat kerja pegawai berada pada kategori sedang mendekati kategori tinggi. Kebanyakan pegawai yang telah menjadi PNS di UPT PSMB - LT Jember merupakan mantan pegawai honorer 
yang telah mengabdi bertahun-tahun pada institusi, dan akhirnya diangkat menjadi PNS. Hal ini menunjukkan bahwa minat mereka untuk bekerja di UPT PSMB - LT Jember telah tertanam sejak lama. Didukung dengan rata-rata pegawai berasal dari Kabupaten Jember sehingga mereka merasa lebih tenang dan nyaman bekerja dekat dengan keluarga.

\section{Motivasi}

Motivasi merupakan dorongan pribadi yang melatarbelakangi pegawai untuk mengembangkan diri. Indikator motivasi pada variabel karakteristik individu berada pada kategori sedang. Ada beberapa hal yang mampu memotivasi pegawai UPT PSMB - LT Jember dalam bekerja, diantaranya adalah dorongan keluarga sebagai motif terbesar pegawai bekerja di UPT PSMB - LT Jember yang lebih besar dibanding motif untuk mengembangkan ilmu pengetahuan dan keterampilan. Dalam hal perkembangan global, kebanyakan pegawai telah siap terhadap perubahan yang terjadi akibat globalisasi akan tetapi masih sedikit pegawai yang mampu beradaptasi dengan perubahan organisasi. Hal ini disebabkan oleh beberapa pegawai yang memasuki usia purna tugas sehingga mereka kurang termotivasi untuk beradaptasi dengan terhadap perkembangan global. Pada variabel karakteristik individu, motivasi menjadi indikator yang memberikan pengaruh terbesar. Oleh sebab itu, pengembangan diri melalui perbaikan karakteristik individu pada aspek motivasi diri perlu dilaksanakan.

\section{Kepatuhan}

Kepatuhan pegawai terhadap peraturan yang berlaku di UPT PSMB - LT Jember berada pada kategori sedang, yang mana $71 \%$ pegawai selalu mentaati peraturan yang diberlakukan intitusi, tetapi sisanya masih pernah tidak mentaati peraturan, seperti peraturan penggunaan seragam lapang dan alat pelindung diri saat melakukan pelayanan di lapang. Berdasarkan instruksi kerja yang ada, semua petugas inspeksi diwajibkan menggunakan peralatan kerja yang memadai sebelum melakukan inspeksi di lapang seperti penggunaan masker, baju tertutup dan sepatu saat inspeksi fumigasi.

\section{KESIMPULAN}

Berdasarkan hasil penelitian dan pembahasan yang berkaitan dengan pengaruh karakteristik individu yang meliputi sikap, minat, motivasi dan kepatuhan terhadap kinerja pegawai UPT PSMB - LT Jember, maka dapat diperoleh kesimpulan sebagai berikut :
1. Hasil penelitian secara parsial, merujuk bahwa variabel sikap, minat, moivasi dan kepatuhan berpengaruh positif dan signifikan terhadap kinerja pegawai dengan variabel motivasi menjadi variabel yang memiliki koefisien korelasi terbesar.

2. Hasil penelitian menunjukkan bahwa secara serempak ada pengaruh yang signifikan antara sikap, minat, motivasi dan kepatuhan terhadap kinerja pegawai dengan $\mathrm{f}$ hitung $>\mathrm{f}$ tabel $(51,448>2,70)$.

\section{SARAN}

Berdasarkan hasil kajian dan pembahasan yang telah dilakukan, maka

untuk meningkatkan kinerja yang dihasilkan oleh pegawai, dapat dilakukan dengan mengembangkan karakteristik individu pegawai utamanya peningkatan motivasinya.

\section{DAFTAR PUSTAKA}

Ghozali, I. 2005. Aplikasi Analisis Multivariate dengan program SPSS. Semarang:Badan Penerbit Universitas Diponegoro.

Lewa, K., I, Idham, Eka dan Subowo. 2005. Pengaruh Kepemimpinan, Lingkungan Kerja Fisik dan Kompensasi Terhadap Kinerja Pegawai di PT. Pertamina (Persero) Daerah Operasi Hulu Jawa Bagian Barat Cirebon. Jurnal SINERGI:Kajian Bisnis dan Manajemen Edisi Khusus on Human Resources.

Mahmodha, SA. 2004. Analisis Karakteristik Individu dan Karakteristik organisasi Terhadap pengembangan Karir Pegawai (Studi Kasus pada Kanwil VII Direktorat jenderal Bea dan Cukai Surabaya),. Tesis. Program Pasca Sarjana Universitas Airlangga. Surabaya.

Marimin, M N. 2010. Aplikasi Teknik Pengambilan Keputusan dalam Manajemen Rantai Pasok. Bogor: PT Penerbit IPB press.

Nazir, M. 2005. Metode Penelitian. Ghalia Indonesia. Bogor.

Nurhastuti, N. 2011. Pengaruh Lingkungan Kerja dan Karakteristik Individu terhadap Kinerja Karyawan. Universitas Sanata Dharma. Yogyakarta.

Robbins, P. S. 2006.Perilaku Organisasi. Edisi kesepuluh, PT Indeks Jakarta.

Winardi, J. 2004. Manajemen Perilaku Organisasi. Edisi Revisi. Jakarta:KencanaWinardi.

Wirawan. 2009. Evaluasi Kinerja Sumber Daya Manusia. Jakarta : Salemba Empat. 
Devi Arieni, Tanti Kustiari dan Suharjono, Pengaruh Karakteristik Individu Terhadap Kinerja Pegawai Di UPT. Pengujian Sertifikasi Mutu Barang-Lembaga Tembakau Jember 